University of Warwick institutional repository: http://go.warwick.ac.uk/wrap

This paper is made available online in accordance with publisher policies.

Please scroll down to view the document itself. Please refer to the repository record for this item and our policy information available from the repository home page for further information.

To see the final version of this paper please visit the publisher's website. Access to the published version may require a subscription.

Author(s): Strand, S. \& Winston, J.

Article Title: Educational aspirations in inner city schools

Year of publication: 2008

Link to published version:

http://www.informaworld.com/smpp/content $\sim$ content=a794616561 db=all order=pubdate 


\title{
Educational aspirations in inner city schools
}

\author{
Steve Strand \\ \& \\ Joe Winston
}

Subsequently accepted for publication in Educational Studies 34, (4) (due Nov 2008)

\author{
$\underline{\text { Address for Correspondence }}$ \\ Dr Steve Strand \\ Associate Professor (Reader) \\ Institute of Education \\ University of Warwick \\ Tel: (024) 76522197 \\ e-mail: steve.strand@warwick.ac.uk
}

Running Head: Educational aspirations in inner city schools

Keywords: Educational aspirations, ethnic group, attitudes, achievement, attainment, gender. 


\section{Educational aspirations in inner city schools}

\section{ABSTRACT}

The research aimed to assess the nature and level of pupils' educational aspirations and to elucidate the factors that influence these aspirations. A sample of five inner city comprehensive secondary schools were selected by their Local Authority because of poor pupil attendance, below average examination results and low rates of continuing in full-time education after the age of 16 . Schools were all ethnically mixed and co-educational. Over 800 pupils aged 12-14 completed a questionnaire assessing pupils' experience of home, school and their peers. A subsample of 48 pupils selected by teachers to reflect ethnicity and ability levels in individual schools also participated in detailed focus group interviews. There were no significant differences in aspirations by gender or year group, but differences between ethnic groups were marked. Black African, Asian Other and Pakistani groups had significantly higher educational aspirations than the White British group, who had the lowest aspirations. The results suggest the high aspirations of Black African, Asian Other and Pakistani pupils are mediated through strong academic selfconcept, positive peer support, a commitment to schooling and high educational aspirations in the home. They also suggest that low educational aspirations may have different mediating influences in different ethnic groups. The low aspirations of White British pupils seem to relate most strongly to poor academic self-concept and low educational aspirations in the home, while for Black Caribbean pupils disaffection, negative peers and low commitment to schooling appear more relevant. Interviews with pupils corroborated the above findings and further illuminated the factors students described as important in their educational aspirations. The results are discussed in relation to theories of aspiration which stress its nature as a cultural capacity. 


\section{INTRODUCTION}

'Addressing poverty of aspiration is necessary to build a society of fairness and opportunity.' (Tessa Jowell, Secretary of State for Culture, 2004, p.15)

A major goal of the UK government in recent years has been to increase the number of young people who continue in education and training after the end of compulsory schooling at age 16 . This is seen as important for the supply of educated and trained labour for the economy, but also for the futures and well-being of the young people concerned (Payne, 2003). Recent Australian research suggests that students' educational aspirations in the early years of secondary school may be important in realising this goal. Khoo \& Ainley (2005) report data from 13,600 young people tracked as part of the Longitudinal Survey of Australian Youth (LSAY) between 1995 and 1998 to show that intentions to complete school formed early in secondary schooling in $Y 9$ (age 13/14) are powerful predictors of actual participation in the latter years of school in Y12 (age 16/17), with a correlation between $Y 9$ intentions and $Y 12$ actual participation of 0.80 . This suggests it may be important to study aspirations in the early years of secondary schooling in order to understand and possibly effect change on later educational participation and attainment. Furthermore, the LSAY research suggests that these educational aspirations in Y9 were themselves strongly influenced by even earlier attitudes to school, which implies that early nurturing of positive attitudes to school even prior to $Y 9$ could be the key to increasing participation in post-compulsory education. Educational aspirations, and the factors that impinge on these aspirations, are therefore in themselves an important outcome which needs to be studied.

There are different theoretical perspectives on the interpretation of educational aspirations and their significance for future behaviour. The dominant model is the 'status attainment' model which stresses aspirations as a cognitive state that motivates or drives young people to strive for academic success. There is a recognition that both personal dimensions (e.g., the impact of significant others, or students' perceptions of their own personal attributes) and social dimensions (e.g., quality of schooling, or parental social class) are important mediating factors (e.g. Alloway et al, 2004). Parents in particular have been seen as the most significant others in shaping aspirations because they provide the opportunities, encouragement and support for their children's learning (e.g., Garg et el. 2002; Hung \& Marjoribanks, 2005; Majoribanks, 2003). However 'economic models' portray educational aspirations as a purely rational assessment of students' economic and social circumstances. Students may aspire to continue in post compulsory education as the result of a realistic evaluation of both 'push' factors, such as the avoidance of unemployment, and 'pull' factors such as higher expected earnings in the long term 
(Leslie \& Drinkwater, 1999). From this perspective educational aspirations have no motivational overtones, they are only a rational judgement based on current economic circumstances.

An interesting point of contrast has been differences in educational aspirations across different ethnic groups. In the US, Kao and Tienda (1998) report no difference between White and Black students at age 14 in their aspirations to complete college (though Asian American students had higher aspirations, and Hispanic students lower aspirations, than both the White and Black groups). However when social class was controlled Black students evidenced significantly higher aspirations than White students, and this finding is widely replicated in US studies (Cheung \& Starks, 2002; Hao \& Bonstead-Bruns, 1998; Mickelson, 1990; Solorzano, 1992). There is surprisingly little quantitative data from the UK, but it seems to conform to this pattern. Penn and Scattergood (1992) studied 15 year old pupils in three Rochdale schools and reported a stronger disposition from Asian pupils to remain within the educational system including going to university. More recently Addams \& Johnson (2005) surveyed a representative sample of 26,000 pupil aged 11 and 14 years in London schools, and for both year groups report that White British pupils were least likely to report they intended to stay in full-time education after age $16(80 \%)$, compared to $90 \%$ of Black and $90 \%$ of Asian pupils ${ }^{1}$.

If educational aspirations reflect socio-economic inequalities, it would be expected that White students, who are on average from more privileged backgrounds (US Census Bureau, 2006; DfES, 2006) would have higher aspirations than other ethnic groups. The fact that the research findings do not show lower aspirations among some minority ethnic groups has led to a range of 'cultural' explanations of ethnic group differences in aspirations, many of which emphasise parental aspirations and cultural orientation towards schooling (e.g., Wentzel, 1998; Francis \& Archer, 2005). For example Khattab (2003) studied minority Palestinian students in Israel and concludes that, despite all the political and economic odds stacked against them, educational aspirations among minority students aged 14-16 remain high due mainly to what he calls 'the social capital within the family that results in norms, values and perceptions regarding the importance of education' and how these impact on students' perceptions of future opportunities. Other authors have emphasised a distinction between 'voluntary minorities' (such as immigrant groups who may be recent arrivals to the US and have very high aspirations) and 'involuntary' or 'caste like' minorities (such as African Americans) who have different orientations (Ogbu, 1978).

The current research was concerned to extend the international data on young people's educational aspirations by adding further data from the UK, particularly from inner city areas

\footnotetext{
${ }^{1}$. Interestingly these figures hardly differed between $Y 7$ and Y10 pupils. Data were not disaggregated within 'Black' and 'Asian' groupings.
} 
where educational aspirations such as rates of continuation in FTE are relatively low. The key research questions addressed were:

- What are the educational aspirations of a sample of pupils from inner city UK schools at age 11 and at age 14 ?

- Are there significant differences in the levels of educational aspirations by gender, age or ethnic group?

- To what extent are educational aspirations correlated with factors in the home, school or peer group?

- Can ethnic group differences in factor scores from the questionnaire account for ethnic group differences in educational aspirations?

\section{METHOD}

The research was undertaken in April 2005, in a selected sample of inner city secondary schools facing significant challenging circumstances. The project assessed educational aspirations among Year 7 (age 12) and Year 9 (age 14) pupils. Year 7 was chosen because it is the first year of secondary school and an important baseline for measuring future changes in aspirations, and Year 9 because it is a transition year where subject choices and other educational decisions that shape future options are made. As well as measuring educational aspirations, the project wanted to explore and better understand the factors that may influence these aspirations. The research adopted a mixed methods approach, using both a large scale questionnaire and focus group interviews in order to allow for both breadth and depth of information.

\section{The project Local Authority and schools}

The project LA is a large city in the West Midlands. It has areas of affluence, but many more of considerable poverty and high levels of deprivation. Unemployment in 2001 was $7.9 \%$, more than double the national average. In some parts of the city this rises to over $20 \%$. The proportion of pupils eligible for FSM is well above average at $34 \%$ compared to $18 \%$ nationally. The city serves an ethnically diverse population with $43 \%$ of pupils drawn from ethnic minorities, well above the national average of $12.1 \%$.

Five of the 76 secondary schools in the city were approached to participate in the project ${ }^{2}$, specifically because of low rates of pupil attendance, poor public examinations results at age 16 and low levels of continuation in post compulsory full-time education (FTE). Even within a fairly

2. One special school was also approached but withdrew with competing external pressures (including an impending OFSTED inspection) given as the reason. 
deprived authority the sample was therefore selected to represent schools facing particularly challenging circumstances. Table 1 summarises the performance data for the five schools. The sample averages were well below national averages on all three measures. In fact for every school on every outcome the results were in the lower quartile (bottom 25\%) of the relevant national school distributions. The pattern of results were a stable feature of each schools performance over the past three years.

TABLE 1: Attendance, examination results and continuation in education post-16 for the project schools against local and national averages

\begin{tabular}{lcccc} 
& Attendance & $\begin{array}{c}\text { Examination } \\
\text { results }\end{array}$ & $\begin{array}{c}\text { Post-16 } \\
\text { destinations }\end{array}$ & Pupil roll \\
\hline School & $\begin{array}{c}\text { average } \\
\text { absence } \\
2003 / 04 \\
\text { academic year }\end{array}$ & $\begin{array}{c}\text { \% 5+GCSE } \\
\text { A*C (incl } \\
\text { English \& } \\
\text { Maths) 2004 }\end{array}$ & $\begin{array}{c}\text { \% remaining in } \\
\text { eductl-time } \\
(2002 / 03 \text { leavers) }\end{array}$ & $\begin{array}{c}\text { pupils } \\
\text { aged 15+ } \\
\text { in 2003/04 }\end{array}$ \\
\hline School 1 & $9.6 \%$ & $18.0 \%$ & $66.7 \%$ & 79 \\
School 2 & $9.4 \%$ & $13.0 \%$ & $67.6 \%$ & 99 \\
School 3 & $15.9 \%$ & $20.0 \%$ & $47.8 \%$ & 238 \\
School 4 & $11.7 \%$ & $12.0 \%$ & $48.4 \%$ & 64 \\
School 5 & $14.8 \%$ & $11.0 \%$ & $40.0 \%$ & 122 \\
\hline Sample average ${ }^{(a)}$ & $13.2 \%$ & $15.9 \%$ & $52.0 \%$ & - \\
Local Authority average & $8.2 \%$ & $37.0 \%$ & $75.1 \%$ & - \\
National average & $8.2 \%$ & $43.0 \%$ & na & - \\
\hline
\end{tabular}

(a) sample averages are weighted by the age 15+ pupil roll.

The pupil questionnaire

A questionnaire was designed to gather consistent quantitative data across the project schools.

Educational aspirations were assessed by asking pupils two direct questions: (a) whether they intended to remain in full-time education (either school or college) after the age of 16; and (b) the level of qualifications they expected to achieve by the end of their education, ranging from no GCSE/GNVQs to university degree.

The questionnaire was also designed to assess factors that may impact upon aspirations, such as: the extent of home support; pupils' experience of school, teachers and the classroom; pupil's attitudes to school and to the future; self-esteem and academic self-concept; and peer influences. Thirty-four items were developed which students rated on a four point scale of 
strongly agree, agree, disagree, or strongly disagree. Item phrasing was varied so that for some items agreement indicated a positive response while for other items agreement indicated a negative response so as to minimise the potential for response bias. The questionnaire also included an open question inviting pupils to comment on any barriers they felt prevented them achieving more at school. The items are given in the results section under 'factor analysis'.

\section{The focus group discussions}

In addition to the questionnaires, more qualitative information was gathered through discussions with focus groups. The questions were structured to tap into students aspirations and expectations, the futures they would like and any difficulties they saw in achieving their goals, the level of support they felt they received from home, school and peers; how ambitious/realistic were their career aspirations; and whether and where they looked to for role models and sources of advice. A total of eight focus group interviews took place, each involving groups of six students, in four ${ }^{3}$ of the schools (a total of 48 interviewees). Schools were asked to choose students to represent the variety of ethnic groups and a mix of ability. Groups varied according to gender make-up in recognition of the fact that young people might talk differently according to the gender mix of the group. This decision also allowed for more gender specific dialogue to take place at times. There were three groups of boys, two groups of girls, and three mixed-sex groups. One male and one female researcher took a group in each school. The male researcher interviewed the all-male groups, the female the all-female groups. The interviews were structured around a common set of questions, but with researchers being flexible enough to allow for students to pursue particular lines of interest. Interviews were conducted in quiet areas of the school and lasted between thirty-five and fifty-five minutes.

\section{RESULTS}

\section{The sample}

Questionnaires were administered by the class teacher to all classes in the relevant year groups. Returns were received from 849 pupils, representing all pupils in attendance on the survey days. A detailed breakdown of the sample is given in Table 2. Just under two-thirds (63\%) were drawn from Y9 with one-third (37\%) drawn from Y7. The sample included $49 \%$ girls and $51 \%$ boys (20 pupils did not record their gender). Pupils were asked to indicate their ethnicity using the main codes of the Pupil Level Annual School Census (PLASC). Just over half (54\%) of the sample were drawn from the White British group. The other $46 \%$ of pupils were drawn from a range of minority ethnic groups, with 19\% from 'Black' groups and 15\% from 'Asian' groups, as detailed in Table 2. The proportion from each of the five schools is also shown.

\footnotetext{
${ }^{3}$. School 5 joined the project after the fieldwork was completed.
} 
TABLE 2: Total sample by pupil background variables

\begin{tabular}{|c|c|c|c|}
\hline Variable & Value & $\mathrm{N}$ & $\%$ \\
\hline \multirow[t]{11}{*}{ Ethnicity } & White British & 462 & 54.4 \\
\hline & White Other groups & 33 & 3.9 \\
\hline & Black African & 61 & 7.2 \\
\hline & Black Caribbean & 57 & 6.7 \\
\hline & Black Other groups & 46 & 5.4 \\
\hline & Indian & 14 & 1.7 \\
\hline & Pakistani & 56 & 6.6 \\
\hline & Bangladeshi & 25 & 2.9 \\
\hline & Asian Other groups & 26 & 3.1 \\
\hline & Chinese & 2 & 0.2 \\
\hline & Any other group & 67 & 7.9 \\
\hline \multirow[t]{3}{*}{ Gender } & Boy & 405 & 48.9 \\
\hline & Girl & 424 & 51.1 \\
\hline & missing & 20 & - \\
\hline \multirow[t]{2}{*}{ Year group } & Year 7 (age 12) & 313 & 36.9 \\
\hline & Year 9 (age 14) & 536 & 63.1 \\
\hline \multirow[t]{5}{*}{ School } & School 1 & 149 & 17.6 \\
\hline & School 2 & 138 & 16.3 \\
\hline & School 3 & 309 & 36.4 \\
\hline & School 4 & 120 & 14.1 \\
\hline & School 5 & 133 & 15.7 \\
\hline
\end{tabular}

Note: Because of the small numbers of Chinese $(n=2)$ and Indian $(n=14)$ pupils, these groups were collapsed with 'Asian other groups' in subsequent statistical analysis.

\section{Factor structure of the pupil questionnaire}

The 34 items of the pupil questionnaire were subject to factor analysis in order to assess the underlying structure in the responses. While items had been created and grouped together on a thematic basis (items related to home, to friends, to school and to self) it was important that the factor scores employed in the analysis emerged from the empirical data, rather than being imposed on an apriori basis. Any pupil who omitted more than three of the 34 items was dropped from the analysis which reduced the sample to 796 pupils. Subsequent analyses were run using mean substitution for missing values ${ }^{4}$.

The Kaiser-Meyer-Olin (KMO) measure of sampling adequacy was .864 and Bartlett's test of sphericity was highly significant $\left(x^{2}=5.054, d f=561, p<.0001\right)$, both statistics indicating the data was appropriate for factor analysis. Principle Components Analysis extracted eight components

\footnotetext{
4. This was important so as not to exclude from subsequent regression analyses those pupils who had omitted only a small number of questionnaire items. As a check, the factor analysis was also completed with listwise data deletion and gave the same eight factor structure.
} 
with eigenvalues $>1$, explaining $49 \%$ of the total variance. Since an underlying aim was to explore any relations between the emerging factors and educational aspirations, we did not attempt to constrain or reduce the number of factors any further. A varimax rotation was applied to more clearly delineate the factor structure. Table 3 shows the eight factors and the 31 items with high loadings (>0.375) on each factor. A label for each factor was inferred from the content of the items loading on the factor.

The first factor is labelled 'commitment to schooling' since the five items identify a belief that school is important to achieve desired career choices, that hard work will aid success in life, that doing well at school is 'important' and that the individual is committed to attend school (unless ill) and works hard at school. The second factor is labelled 'Academic self-concept' since the six items assess positive self-evaluations in relation to success as a learner and problem solver. The third factor is labelled 'teacher support' since the three items with the strongest loadings all relate to the actions of teachers in support of learning. The fourth factor is labelled 'Home-support for learning' since the five items all describe action in the home that support learning. The fifth factor is labelled 'positive peer support' since the items indicate that friends think school is important, help with school work and intend to continue in education post-16. This is contrasted with the sixth factor 'disaffection-negative peers', which indicates feeling bored in class, wanting to leave school and get a job, and having friends that distract you and who laugh at those who do well at school $^{5}$. The seventh factor is composed of only two items and, while somewhat ambiguous, is labelled 'laissez faire' since the items indicate that no decisions need to be made about the future and that success at school will not make much difference to later life. The final factor is labelled 'Home-educational aspirations' and is also composed of only two items. These items assess whether parents/carers think school is important and whether people from the family go to college after they leave school. This factor emerges separately from the fourth factor, 'homesupport for learning', suggesting that parents can actively support the learning process without necessarily viewing school as important or having a tradition of continuing education.

5. Note that the factor analysis identifies Factors 5 and 6 as two distinct factors, not opposite poles on a single factor. 
1 Commitment to schooling

$\begin{array}{ll}\text { Finishing school is important to achieve my career choice } & 0.695\end{array}$

If I work I can succeed in life $\quad 0.633$

Doing well at school is important to me $\quad 0.623$

I always attend school unless I'm ill $\quad 0.537$

$\begin{array}{ll}\text { I work hard at school } & 0.403\end{array}$

2 Academic self-concept

$\begin{array}{ll}\text { If I get stuck, I can usually work things out } & 0.744\end{array}$

$\begin{array}{ll}\text { I am good at solving problems } & 0.685\end{array}$

I feel good about myself $\quad 0.591$

I know how to be a good learner $\quad 0.570$

$\begin{array}{ll}\text { I am good at most subjects at school } & 0.538\end{array}$

$\begin{array}{ll}\text { I am good at working with others } & 0.420\end{array}$

3 Teacher support

$\begin{array}{ll}\text { Teachers do their best to make lessons interesting } & 0.773\end{array}$

$\begin{array}{ll}\text { I am praised by teachers when I do well } & 0.760\end{array}$

$\begin{array}{ll}\text { Teachers show an interest in me } & 0.714\end{array}$

$\begin{array}{ll}\text { I can choose interesting work at school } & 0.418\end{array}$

4 Home- support for learning

$\begin{array}{ll}\text { Family members/carers help me with homework } & 0.659\end{array}$

Family members/carers reward me if I do well at school $\quad 0.619$

Family members/carers often ask me how I'm doing at school $\quad 0.611$

I have a quiet place in which to do school work $\quad 0.423$

$\begin{array}{ll}\text { Family members/carers usually come to open evenings/reviews } & 0.377\end{array}$

5 Positive peer support

$\begin{array}{ll}\text { My friends think doing well at school is important } & 0.690\end{array}$

My friends help me with school work $\quad 0.632$

Most of my friends intend to stay at school/college after year $11 \quad 0.630$

6 Disaffection/negative peers

I want to leave school as soon as possible and get a job 0.686

$\begin{array}{ll}\text { I often get bored in class } & 0.549\end{array}$

My friends distract me from paying attention in school $\quad 0.533$

$\begin{array}{ll}\text { My friends laugh at those who do well at school } & 0.456\end{array}$

7 Laissez faire

I think it's OK not to know what to do with my future 0.766

How well I do at school won't make much difference to my life 0.483

8 Home- educational aspirations

$\begin{array}{ll}\text { People from my family go to college after they leave school } & 0.689\end{array}$

$\begin{array}{ll}\text { Family members/carers do not think that school is very important } & 0.438\end{array}$

Notes: three items which did not load $>0.375$ on any factor are excluded from the table. 
Factor scores were calculated to give pupils a numeric score for each. These scores have a mean of zero and standard deviation of one for the sample as a whole.

\section{Educational aspirations}

\section{Intention to continue in full-time education (FTE) after age 16}

Pupils were asked whether they intended to continue in full-time education (FTE), either at school or college, after age 16. The question was answered by 773 (91\%) of students.

Aspirations were high, with 85\% giving a positive response. Figure 1 plots the results by ethnic group. Overall, the White British group had the lowest aspirations, with only $80 \%$ of pupils indicating an intention to remain in FTE, and rose to $97 \%$ for Asian Other and 98\% for Black African pupils.

\section{FIGURE 1: intention to continue in FTE after age 16 by ethnic group}

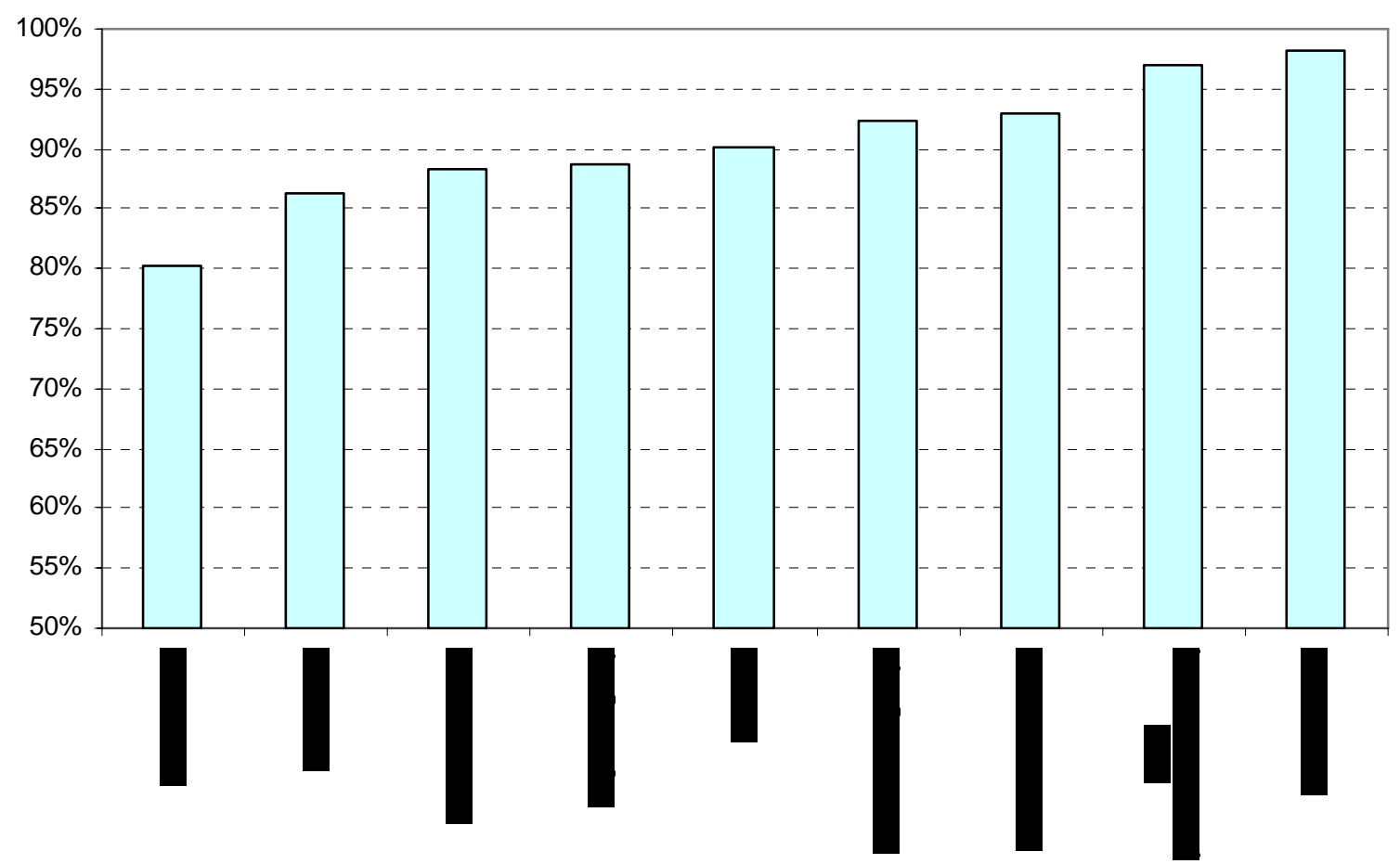

A logistic regression was completed to determine the relationship between the pupil background variables (gender, ethnicity, year group and school) and intention to continue in FTE. The model includes dummy variables for each ethnic group contrasted against the majority White British group, and for each school contrasted against the largest school (School 3). The results are presented in Model 1 of Table 4. 
There was no significant association between gender or year group and intention to continue in FTE. However Black African pupils were over 10 times more likely than White British pupils to say they intended to stay in FTE (both $p<.05)$. The terms for Asian Other $(p<.09)$ and for School $1(p<.06)$ were close to significance. There were no significant ethnic by gender or ethnic by year interaction terms (for purposes of clarity these interaction terms are not shown in the table).

TABLE 4: Logistic regression of ethnic group, gender, year group and factor scores on intention to continue in full-time education after age 16

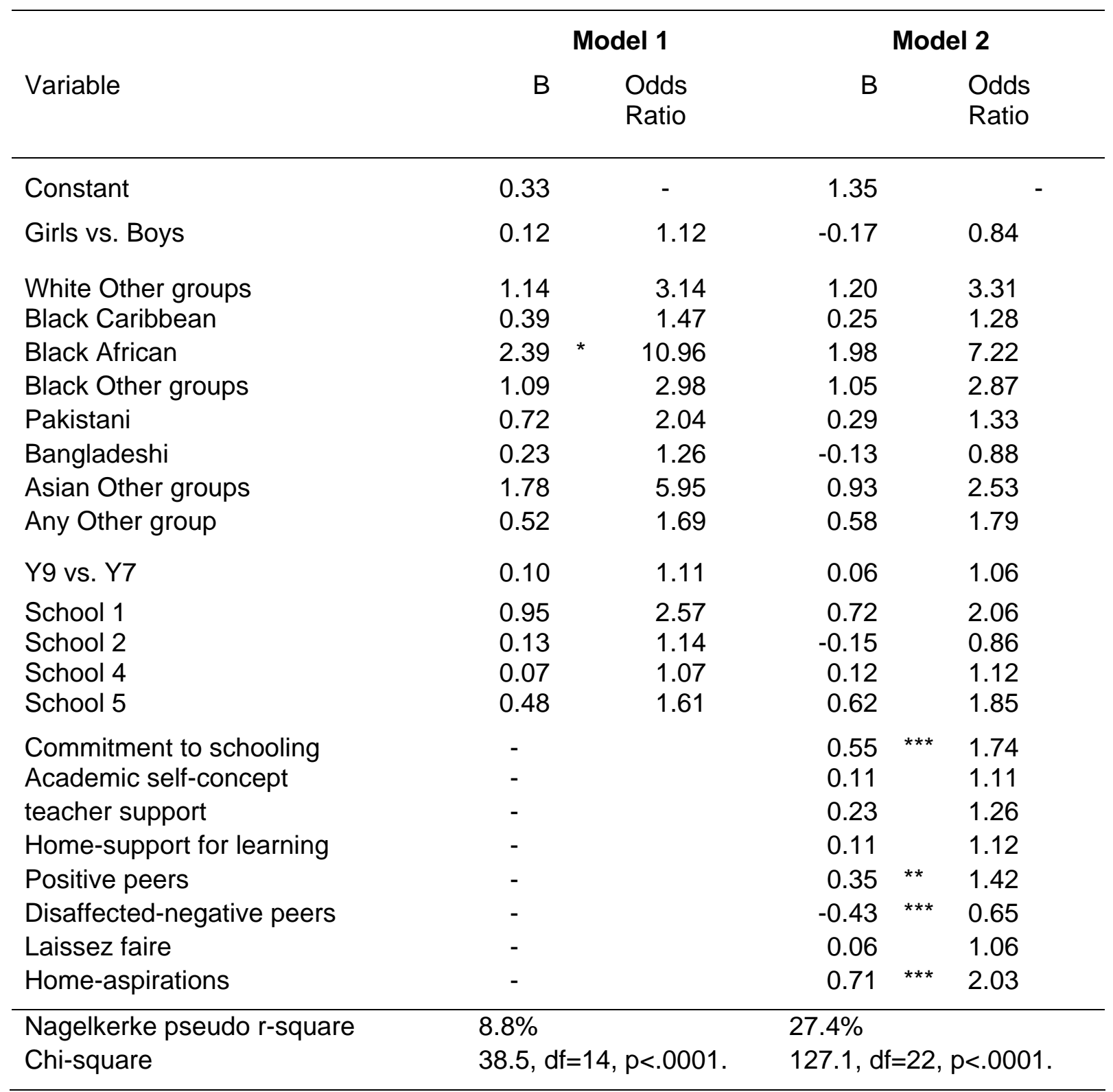

Notes: The coefficients for ethnic groups are contrasts with the majority White British group. The school coefficients are contrasts with the largest school (school 3). ${ }^{*}=p<.05 ;{ }^{* *}=p<.01,{ }^{* * *}=p<.001$.

Overall pupil background explains relatively little (9\%) of the variance in intention to continue in FTE. Table 4, Model 2 adds the eight factor scores and this increases the explanatory power of the model threefold accounting for around $27 \%$ of the variance. Four factor scores had significant 
associations with intention to continue in FTE: high commitment to schooling, high positive peer support, low disaffection-negative peers and high home-educational aspirations $(p<.01$ in all cases). An indication of the size of the effects can be gained by examining the odds ratios (OR), which show the change in likelihood of aspirations to continue in FTE associated with a one SD change in factor score. The largest impact was for home educational aspirations, where pupils with a factor score one SD above the mean were four times more likely to continue in FTE than pupils with a factor score one SD below the mean. Equally pupils with a 'disaffection-negative peers' factor score one SD above the mean were three times less likely to continue in FTE than pupils with a factor score one SD below the mean ${ }^{6}$. Similar effects was apparent for the other two significant factor scores. Interestingly the coefficient for Black African was no longer statistically significant once the factor scores were included, indicating the factor scores could statistically explain this difference in aspirations. This will be discussed further below.

\section{Level of qualifications expected by the end of education}

Pupils were asked "what level of qualifications do you expect to achieve by the end of your education"? and asked to select one of five options, ranging from 'no GCSEs' through to 'University Degree'. A total of 751 pupils (88\%) answered the question and the results are presented in Table 5. Aspirations were high, with all but five pupils expecting to achieve some GCSEIGNVQ examination passes. Overall, $85 \%$ of pupils expected to achieve 5 or more 'good' GCSE passes (grades $A^{*}-C$ ) or better, $56 \%$ expected to achieve 'A/AS' levels or above, and 37\% aspired to achieve a University degree.

TABLE 5: What level of qualifications do you expect to achieve by the end of your education?

\begin{tabular}{lrrr}
\hline Level of qualification expected & $\mathrm{n}$ & Valid \% & $\begin{array}{r}\% \text { this } \\
\text { level or } \\
\text { above }\end{array}$ \\
\hline No GCSE/GNVQ passes & 5 & 0.7 & 100.0 \\
Some GCSE/GNVQ passes & 110 & 14.6 & 99.3 \\
Five or more 'good' GCSE/GNVQ passes & 215 & 28.6 & 84.7 \\
'A/AS' levels & 144 & 19.2 & 56.1 \\
University degree & 277 & 36.9 & 36.9 \\
\hline Total & 751 & 100.0 & \\
\hline
\end{tabular}

\footnotetext{
6 . The way odd-ratios are expressed depends on the base or reference category. The ratio $A: B$ can equally be expressed as the ratio $B: A$. Thus a ratio of 0.5:1 ( $A$ is half as likely as $B$ ) is symmetrical and equivalent to a ratio of 1:2.0 ( $B$ is twice as likely as $A$ ). To express all odds ratios in a common direction the comparator category can be reversed when a factor has a negative association with aspirations.
} 
Figure 2 displays the cumulative percentages expecting to achieve each level or higher by ethnic group. Thus $28 \%$ of White British pupils aspired to a university degree compared to $50 \%$ of Bangladeshi, $53 \%$ of Black African, $58 \%$ of Pakistani and $66 \%$ of Asian Other groups. Similarly around $50 \%$ of the White British group expected to gain A/AS levels or higher, compared to around three-quarters of pupils among the above mentioned ethnic groups.

\section{FIGURE 2: Cumulative percentage of pupils expecting to gain each level or higher by ethnic group}

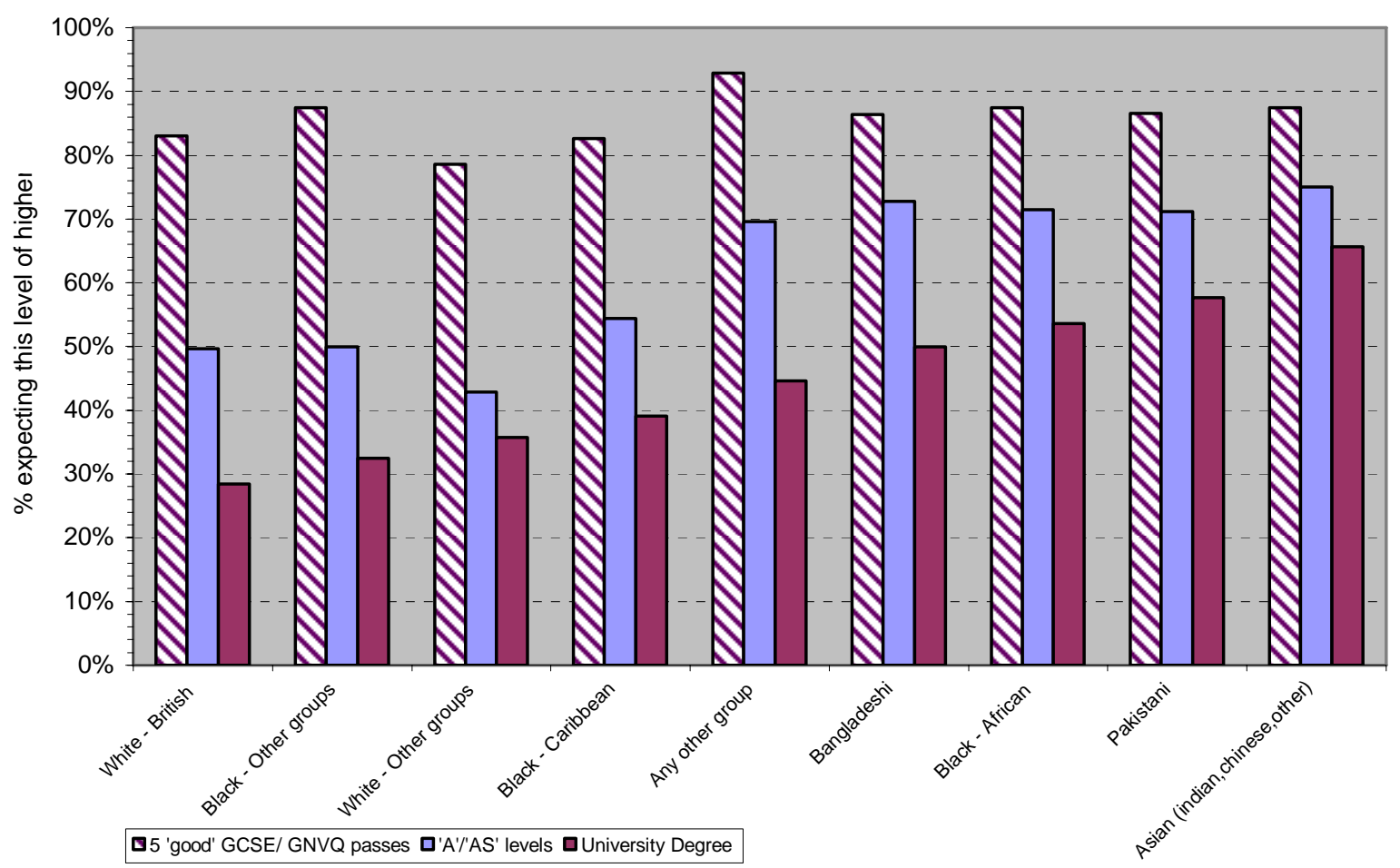

An ordered logistic regression ${ }^{7}$ was completed to determine the relationship between the pupil background variables and level of qualifications expected. Because of the small number of pupils expecting no GCSE/GNVQs the first two categories were collapsed to give four levels. The results are presented in Model 1 of Table 6. Girls had slightly higher aspirations than boys, but the difference was not statistically significant. Equally there was no statistically significant difference between year groups. However, as with intention to continue in FTE post 16, there were substantial associations with ethnic group. Compared to the White British group, expectations were significantly higher within the Black African, Pakistani, Asian Other groups (all $p<.001)$. Aspirations in School 1 were also significantly higher than in the comparator schools $(p<.01)$.

\footnotetext{
7. The PLUM procedure within SPSS V13 was employed.
} 


\begin{tabular}{|c|c|c|c|c|c|c|}
\hline \multirow[b]{3}{*}{ Variable } & \multirow{2}{*}{\multicolumn{3}{|c|}{ Model 1}} & & & \\
\hline & & & & \multicolumn{3}{|c|}{ Model 2} \\
\hline & \multicolumn{2}{|l|}{ B } & $\begin{array}{l}\text { Odds } \\
\text { Ratio }\end{array}$ & \multicolumn{2}{|l|}{ B } & $\begin{array}{l}\text { Odds } \\
\text { Ratio }\end{array}$ \\
\hline Girl vs. Boy & \multicolumn{2}{|l|}{0.20} & 1.22 & \multicolumn{2}{|l|}{0.22} & 1.25 \\
\hline White Other groups & \multirow{2}{*}{\multicolumn{2}{|c|}{$\begin{array}{r}-0.10 \\
0.06\end{array}$}} & 0.90 & \multicolumn{2}{|l|}{-0.27} & 0.76 \\
\hline Black Caribbean & & & 1.06 & \multicolumn{2}{|l|}{-0.03} & 0.98 \\
\hline Black African & \multirow{2}{*}{\multicolumn{2}{|c|}{$\begin{array}{l}0.64 \text { * } \\
0.06\end{array}$}} & 1.90 & \multicolumn{2}{|l|}{0.26} & 1.30 \\
\hline Black Other groups & & & 1.06 & \multicolumn{2}{|l|}{0.08} & 1.09 \\
\hline Pakistani & 0.92 & $\star \star \star \star ~$ & 2.52 & \multicolumn{2}{|l|}{0.64} & 1.89 \\
\hline Bangladeshi & \multicolumn{2}{|c|}{0.52} & 1.68 & \multicolumn{2}{|l|}{0.62} & 1.86 \\
\hline Asian Other groups & 1.18 & $\star \star \star \star ~$ & 3.24 & 0.93 & * & 2.53 \\
\hline Any Other group & \multicolumn{2}{|l|}{0.55} & 1.73 & \multicolumn{2}{|l|}{0.55} & 1.74 \\
\hline Y7 vs. Y9 & \multicolumn{2}{|l|}{-0.09} & 1.09 & \multicolumn{2}{|l|}{0.24} & 1.28 \\
\hline School 1 & 0.71 & $\star *$ & 2.03 & 0.63 & * & 1.88 \\
\hline School 2 & \multicolumn{2}{|c|}{-0.03} & 0.97 & 0.03 & & 1.03 \\
\hline School 4 & \multicolumn{2}{|l|}{0.18} & 1.20 & \multicolumn{2}{|l|}{0.29} & 1.34 \\
\hline School 5 & \multicolumn{3}{|l|}{-0.05} & \multicolumn{2}{|l|}{0.03} & 1.03 \\
\hline Commitment to schooling & \multicolumn{3}{|l|}{-} & 0.41 & 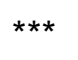 & 1.51 \\
\hline Academic self-concept & \multicolumn{3}{|l|}{-} & 0.35 & $\star \star \star ~$ & 1.42 \\
\hline teacher support & \multicolumn{3}{|l|}{-} & \multicolumn{2}{|l|}{-0.04} & 0.96 \\
\hline Home-support for learning & \multicolumn{3}{|l|}{ - } & \multicolumn{2}{|l|}{0.02} & 1.02 \\
\hline Positive peers & - & & & 0.02 & & 1.02 \\
\hline Disaffected-negative peers & - & & & -0.35 & 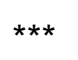 & 0.70 \\
\hline Laissez faire & - & & & -0.08 & & 0.93 \\
\hline Home-aspirations & - & & & 0.16 & * & 1.17 \\
\hline Nagelkerke pseudo r-square & $7.4 \%$ & & & $18.4 \%$ & & \\
\hline Chi-square & $52.6, d$ & $=14$, & $p<.0001$ & $137.9, \mathrm{df}=$ & $22, p$ & K.0001 \\
\hline
\end{tabular}

Notes: The coefficients for the ethnic groups are contrasts with the majority White British group. The school coefficients are contrasts with the largest school (school 3). ${ }^{*}=p<.05 ;{ }^{* \star}=p<.01,{ }^{\star \star *}=p<.001$.

However ethnicity, gender, year group and school explained relatively little (7\%) of the variance in level of qualifications expected. Model 2 in Table 6 adds the eight factor scores and this increases the explanatory power of the model nearly threefold to account for over $18 \%$ of the variance. Four factors had significant associations with level of qualification expected: high commitment to schooling, high academic self-concept, low disaffection-negative peers (all $p<.001)$ and high home-educational aspirations $(p<.05)$. An indication of the size of the effects can be seen in the odds ratios (OR). Thus a 'commitment to schooling' factor score 1SD above the mean as opposed to 1 SD below the mean was associated with a threefold increase in continuation odds (i.e. from some GCSEs to five 'good' GCSEs, or from five 'good' GCSEs to 
A/AS, or from A/AS to University Degree $)^{8}$. A similar size of effect was apparent for academic self-concept and for disaffected-negative peers. The effect was somewhat smaller (1.2:1) for home-educational aspirations.

Again the differences between ethnic groups were substantially reduced once the factor scores were included. The coefficients for Black African and Pakistani were longer significant, and the coefficient for Asian Other reduced to $p<.05$, although this indicates the factor scores could not completely account for the differential aspirations of the Asian Other group relative to White British. The higher aspirations in school 1 were also not completely explained.

\section{Interpreting ethnic group differences in educational aspirations}

Educational aspirations were lowest among White British pupils. They were highest among Black African and Asian Other groups, both on measures of continuing in FTE post 16 and level of qualification expected at the end of education. Pakistani pupils also had significantly higher aspirations than White British pupils in terms of level of qualification, primarily from the high proportion expecting to achieve a university degree.

The questionnaire identified several factors that were strongly associated with educational aspirations. Commitment to schooling, high academic self-concept, positive peer support, the absence of disaffection-negative peers and high educational aspirations in the home were the most powerful predictors of high educational aspirations. Pupils with above average scores on these factors were three to four times more likely to have high educational aspirations, relative to pupils with below average scores. Importantly these factors also statistically explained a substantial part of the ethnic group differences in aspirations. Therefore ethnic group differences in the factor scores may mediate, or at least illuminate the origins of, the ethnic differences in aspirations. Figure 3 presents the mean factor scores for each ethnic group on the five factors which were significantly related to educational aspirations. There are clear ethnic group differences with regard to the factor scores.

The White British group had the lowest educational aspirations. They also had the lowest score of all ethnic groups for both 'academic self-concept' and for 'home-educational aspirations'. They had the second lowest score for 'positive peer support'.

8. Because the factor scores are continuous variables, the effect size is estimated by comparing the probabilities for a student scoring one SD below the mean with the probabilities for a student scoring one SD above the mean, i.e. a two SD range (see Strand, 2004). 
The Black African group had significantly higher aspirations than White British. They had the highest score of any ethnic group for both 'commitment to schooling' and for 'academic selfconcept'. They also had a very high mean score for 'positive peer support' and 'homeeducational aspirations' and a very low score for 'disaffection-negative peers'.

The Asian Other group had significantly higher aspirations than White British. They has the highest mean score of any ethnic group for both 'positive peer support' and 'home-educational aspirations'. Although their mean 'academic self-concept' score was not particularly marked, the 'commitment to schooling' score was as high as the Black African group.

The Pakistani group also had high significantly higher aspirations than White British in regard to educational qualifications. They had the lowest score of any ethnic group for 'disaffectionnegative peers'.

The Black Caribbean group had the highest mean score for 'disaffection-negative peers' and the second lowest mean score for 'commitment to schooling'.

These results suggest the high aspiration of Black African and Asian Other pupils are mediated through strong academic self-concept, positive peer support, a commitment to schooling and high educational aspirations in the home. They also suggest that low educational aspirations may have different mediating influences in different ethnic groups. The low aspirations of White British pupils seem to relate most strongly to poor academic self-concept and low educational aspirations in the home, while for Black Caribbean pupils disaffection, negative peers and low commitment to schooling appear more relevant.

Gender differences were observed for three of the factor scores. Boys had a lower mean score than girls on academic self-concept $(t=3.60, d f=781, p<.0001)$, positive peer support $(t=-5.80$, $d f=782, p<.0001)$, and a higher mean score on disaffection-negative peers $(t=2.95, d f=781$, $p<.0001)$. Although girls had slightly higher aspirations than boys, as is generally reported in the literature (e.g., Addams \& Johnson, 2005), the results were not statistically significant. 
Figure 3: Mean scores by ethnic group on the five factors related to educational aspirations
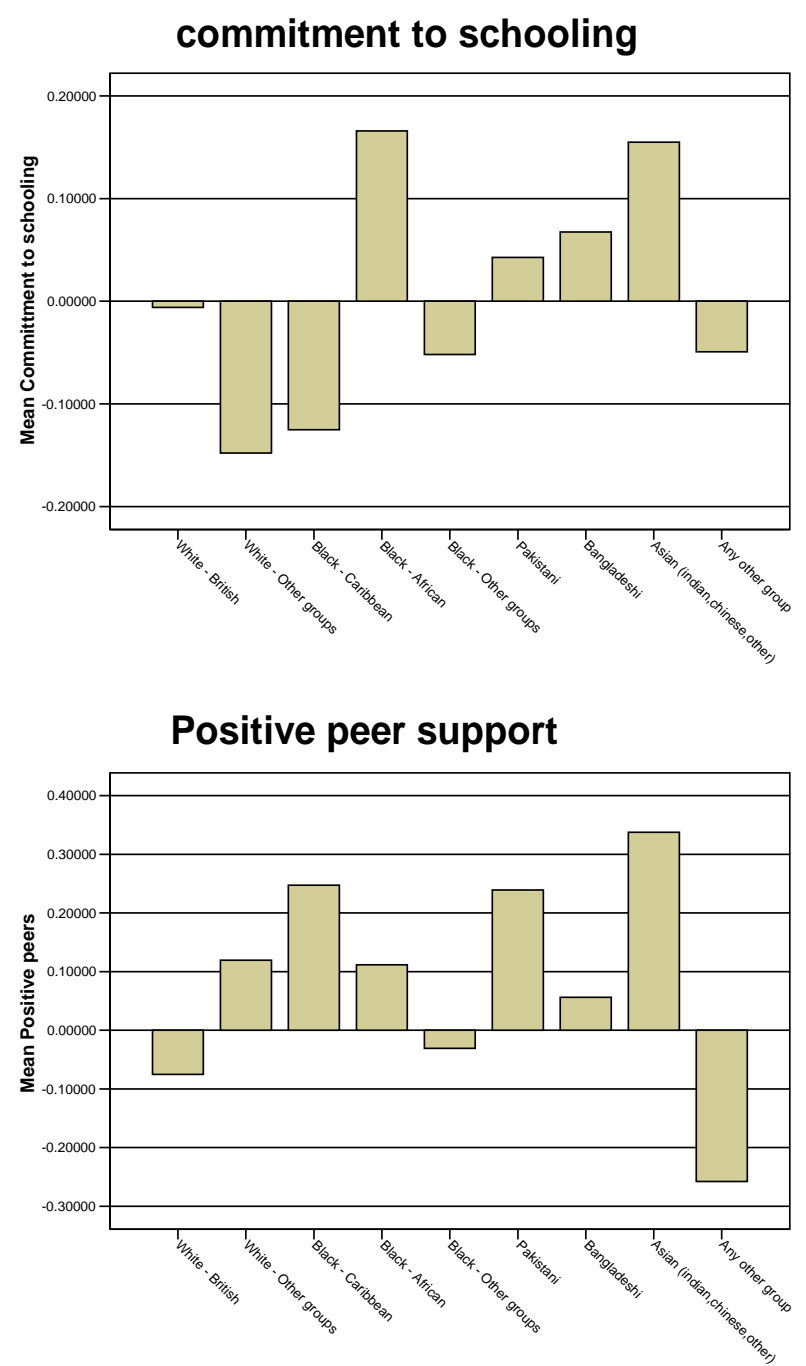

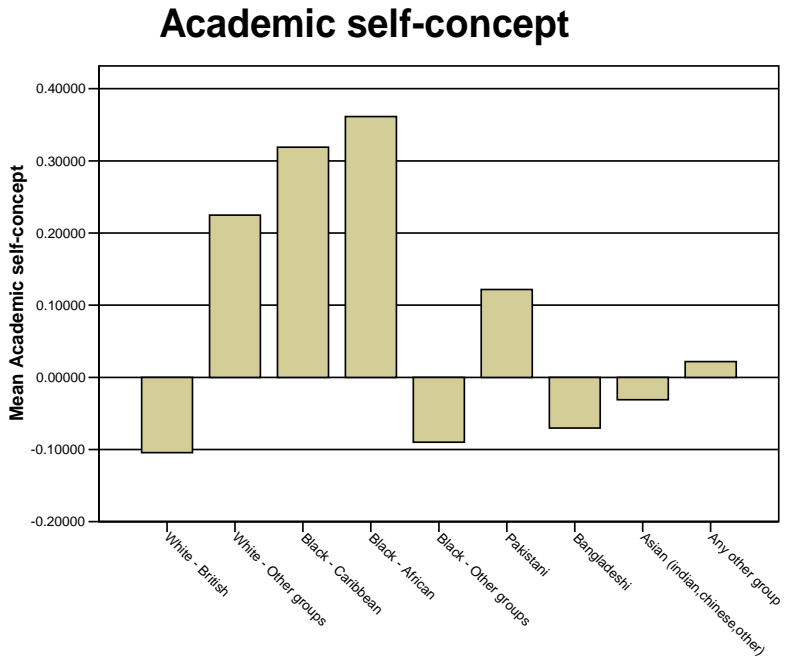

Disaffection-negative peers

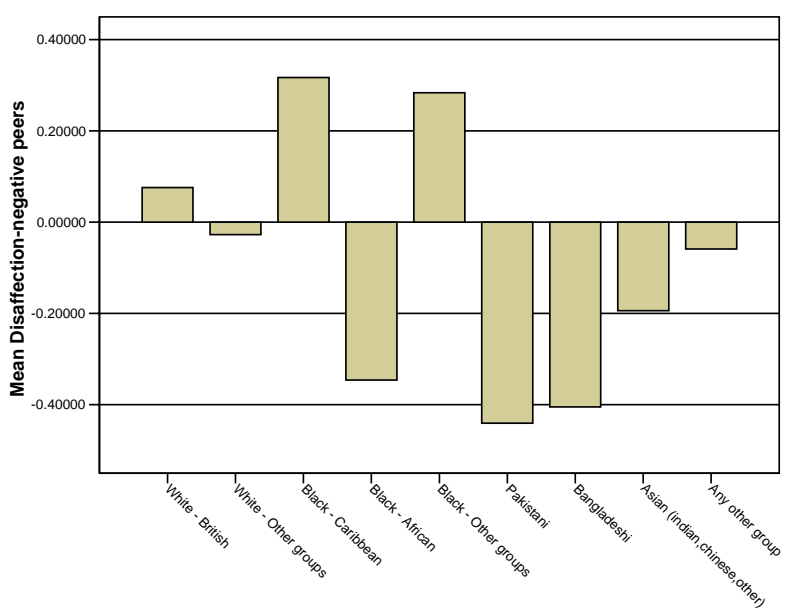

Home-educational aspirations

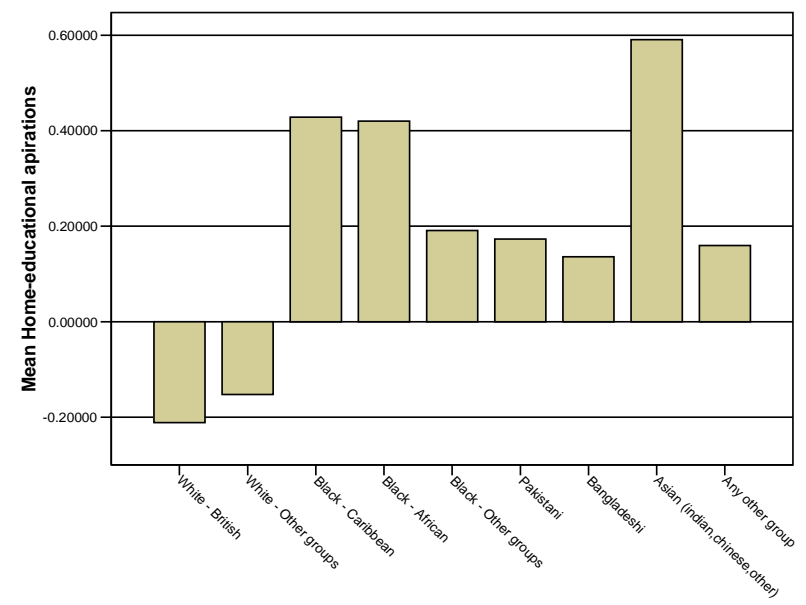




\section{Focus Group Discussions}

The focus group discussions further highlighted the importance of the above factors whilst illuminating the social and cultural issues that underpinned attitudes. White British students generally spoke with less enthusiasm about their education and gave little evidence of high parental aspirations. One group of Year 7 girls, for example, all of whom were White British, displayed little connection with a learning culture, agreeing with their friend who said 'Learning new things won't change anything.' They admitted to liking their English lessons only because 'the teacher lets you do whatever you want. I don't learn anything in the English class.' Although they all said they would go to college when they left school, most of them immediately agreed with the contradictory statement of the girl who ventured that she wanted 'to have a husband and some kids' as soon as she left. They spoke strongly about their loyalty as friends ('I stick with my friends and I stick up for them') but this support was not directed at school work. None of them spoke of their parents as displaying any interest in their schooling. In a different group, a White British girl in Year 9 spoke disparagingly both about her school ('I like nothing about this school') and her mother ('She's more interested in the telly than she is in me.') In all the focus groups only one White British girl spoke of a parent showing real interest in her work ('My stepmother does my homework for me ... she teaches it to me as we go along.') but she was resistant to her real mother's ambition for her to train as a teacher, wanting instead to be a hairdresser, and her stepmother supported her in this. When White British students spoke of feeling supported or valued in the home, it was usually in terms unrelated to school work. Two Year 9 boys, for example, spoke of their fathers being pleased with them because they helped them with jobs about the house. A Year 7 girl was seen as responsible enough to live with her nan and, in effect, was acting as her carer. These examples contrast strongly with a Year 9 Asian Other girl whose mother had opened a bank account for her in order to finance her college education.

A group of White British boys in Year 9 spoke in overall positive tones of their school but all of them aspired to being tradesmen (builders, decorators, plumbers) like their fathers and it was clear that this was what their families expected of them. None of them wanted to go to university although one of them was definite about going to college to train as a plumber. This contrasted with a Black African boy and a Hong Kong Chinese boy in the same focus group. Both were recent immigrants to the country and both had ambitions to go to university as a definite future priority. As the Chinese boy said 'I'll definitely go to university when I leave school. I'll do science or maths perhaps. It depends on my results.' Such ambitions seemed stirred by parental aspiration and cultural experience. For example, when one of the boys spoke of wanting to become a carpenter, the Black African boy said 'To be a carpenter in my country is rubbish. It doesn't pay. People want to work in offices.' 
The focus group discussions provided strong evidence to support the importance of the subtle but substantial distinction between Home Support for Learning and Home Educational Aspirations (see Table 3). Two Black African boys in Year 7 were in a school where targets were set for individual lessons. Not only were their parents interested in these targets but also gave material rewards to the boys if they were met. One of these boys was from Somalia and lived with his mother, who had very clear ambitions for him that re-enforced a sense of personal identity and he was happy to embrace them. 'She wants me to be a doctor so I can help people from my country.' All six of the boys in this particular group were African, Pakistani or Asian Other and all but one displayed high home-educational aspirations which tended to include extended families of aunts, uncles and cousins. One boy, for example, knew about Further Education courses from talking with his two older cousins; another knew he wanted to study accountancy at a local university like his brother; a third, encouraged by his father, wanted to study 'something to do with computers' at university. This particular school, they told me, was in an area where it was 'not good to grow up'. There were fights outside the school gates, they said, and 'fights with knifes and chains and that' outside the local pub. Nevertheless, they were genuinely surprised when asked whether their friends ever laughed at them for working hard or doing well in their lessons. There was little sense of disaffection among their peers and they displayed a positive academic concept, re-enforced by high educational aspirations in extended family networks.

The focus group interviews supported the conclusion that ethnicity was a significantly greater influential factor than gender in students' visions of their future education. So Pakistani and Asian Other girls as well as boys were far more likely to display educational aspirations that were both higher and better informed than their White British or Black Caribbean counterparts. In one Year 7 all-girl group for example, a Black Caribbean girl's desire to become a famous singer, in which she considered school performance was irrelevant, could be contrasted with a Bangladeshi girl's ambition to go to college and study biology in order to become a nurse, and the clearly mapped out aspiration of a Pakistani girl 'I want to work for a company that does trade and contracts so I can travel a bit. So I need to be good at business studies, maths and English.' She added 'My cousins told me you've got to be good at school and you can go to college because if you study then you make your life better', thus displaying the strong influence of home-educational aspirations similar to the group of Year 7 African and Asian boys. Like them she was from a practising Muslim background. Another Black Caribbean girl spoke of her future in terms of another fantasy scenario, as though school were an impediment rather than a scaffold. 'Nothing can hold you back. When I've left school I will be able to follow my dreams. I can be a business woman while starting a family.' A Black Caribbean boy, who aspired to be a professional 
footballer, was sceptical about the relevance of education. He was interested in earning money: 'You can't do much without money'. So would doing well at school help earn money? 'Depends on what you want to do' was his cool response.

This similarity of response in the focus groups between boys and girls from similar ethnic backgrounds extended to their ideas about future careers. White British boys and girls displayed aspirations for less professional jobs; for boys this took the form of a trade, such as a plumber or an electrician, for girls the two most popular were nursery nursing and hairdressing. In contrast, boys from Black African, Pakistani and Asian Other backgrounds generally aspired to work in the professions, particularly medicine, or with computers, and girls in these groupings had similar professional aspirations, as illustrated above.

\section{Discussion and conclusions}

The research has raised new perspectives on educational aspirations in an inner urban area. It supports other research which points to young people's ethnicity as a key factor associated with their level of educational aspiration, and also suggests a number of mediating factors. High among these is what we have termed 'home-educational aspirations', the level of expectation among parents but also from extended family groupings. Similar observations have been made by other authors (Francis \& Archer, 2005; Khattab, 2003; Wentzel 1998). Cheng and Starks (2002, p.322) see aspirations in the home as especially important when the young people concerned lack the material or cultural resources of the more privileged middle classes. The research suggests that the dominant White British working class attitude in the inner city area studied, while not necessarily negative to schooling, tended to see education as less significant in achieving their vocational goals. Career aspirations among ethnic minority groups on the other hand tended more towards the professions and consequently their educational aspirations were higher. Nor were these aspirations necessarily unrealistic. A number of the young people who spoke of having such aspirations mentioned family or extended family members as role models, including some who were at university.

For the White British children, the capacity to aspire appears to be more readily constrained by their social class; and class as well as ethnicity is a strong cultural carrier of norms and values (Bourdieu \& Passeron, 1977). A study by McLeod (1995) of two gangs of adolescent boys, one White, the other Black, both from the same deprived, inner city neighbourhood in the US, suggests a possible reason for this constraint. The white teenagers showed the lowest aspirations and all came from families who had lived longest in the neighbourhood. McLeod emphasises this as particularly significant when analyzing their attitudes, which he sees as 
demonstrative of immobility and stagnation. When interviewing these boys and their parents, he found none of the language of hope that he found in the families of the black teenagers. Parents of the white boys were reticent in fostering high aspirations for their children; they saw them as unrealistic and did not want their children to experience disappointment, frustration and feelings of failure. By contrast, the parents of the black teenagers, all of whom were relatively recent arrivals in the neighbourhood, encouraged them to aspire to middle class values and norms, a practice which Robert Merton has called 'anticipatory socialization'. ${ }^{9}$ This study suggests that those groups who have been located for longest within an area of social deprivation may feel more reluctant to embrace the educational aspirations that promise an escape from it. It also suggests a reason why the White British boys in the focus groups aspired only to typically working class jobs, whilst those Black African and Asian children whose families were more recent arrivals to the country demonstrated high levels of both educational and career aspiration.

The word 'culture' is significant here. As Fenton points out, the key distinction between the terms ethnicity and race is that for the former 'the point of reference of difference is typically culture rather than physical appearance' (Fenton, 2003, p.23). Appadurai (2004) argues that the capacity to aspire is a cultural capacity; by this he means that it finds expression in what he terms 'densely local ideas' - about marriage, work, leisure and the good life in general - and that these are mediated through strongly normative and localised cultural contexts (2004, p.68). He sees the capacity to aspire as essentially a 'navigational capacity .. nurtured by the possibility of real-world conjectures and refutations' (p.69). Those groups that are able 'to explore the future more frequently and more realistically, and to share this knowledge with one another more routinely' are the groups that are able to map these norms more successfully and therefore to aspire more constructively. Appadurai sees these groups as generally the more socially privileged but this research suggest that, within deprived inner city areas, children of different ethnic backgrounds may expect different levels of navigational guidance with regard to realistic pathways connecting learning, achievement and career choices. This might help explain the mismatch between aspiration and attainment, for example $80 \%$ of White British students aspired to achieve five or more good GCSEs, but the most recent results for the sample schools indicated that only $34 \%$ of pupils achieved this. This was further illuminated by the focus group interviews, where the connection between learning, examination results and career choices was more erratic among White British and Black Caribbean pupils when compared to their Black African and Asian counterparts.

These results are specific to an inner urban area, and may not generalise to the national population. The social class composition of the White British population in inner urban areas is

\footnotetext{
${ }^{9}$ See McLeod (1995) pp. 57-59; 110.
} 
not representative of the social class composition of White British more generally, being skewed towards working class backgrounds (Strand, 1999). However a recent analysis of a nationally representative sample of 15,000 pupils in the Longitudinal Study of Young People in England (LSYPE) revealed a very similar pattern of ethnic group difference in educational aspirations at age 14 , with $77 \%$ of White British pupils aspiring to continue in FTE after 16 , compared to $86 \%$ of Black Caribbean, 91\% of Pakistani, 92\% of Indian, 92\% of Bangladeshi and 95\% of Black African pupils (Strand, 2007). The study also showed that parental aspirations for their children to continue in FTE after age 16, and the pupil's own aspirations to do so, were both strongly correlated with educational attainment and with educational progress between age 11 and age 14.

However the LYPSE study also presents an example of what has been termed the 'AttainmentAspirations' paradox (Mickelson, 1990), in that while Black African, Pakistani and Bangladeshi groups had the highest educational aspirations there were also the groups with the lowest educational attainment at age 14. Of course there is no paradox if aspirations are stripped of their causal role in relation to attainment. High levels of intending to continue in FTE among some minority groups may actually reflect students knowledge of the greater risk of unemployment for young members of minority ethnic groups relative to Whites if they enter the labour market at 16, together with the fear of racial discrimination in the workplace (Payne, 2003). White British students may have lower 'aspirations' because they do not face these barriers. Using Mickelson's (1990) distinction between abstract aspirations and concrete attitudes, pupils from Black, Pakistani and Bangladeshi ethnic groups may evidence high aspirations in the form of general ideological beliefs about the value of education (e.g., "education is the key to success in the future"). However their concrete attitudes, derived from their experience of unequal returns to education for their family or community (e.g. "people in my family haven't been treated fairly at work no matter how much education they have"), may be lower than their White peers, and according to Mickelson it is these attitudes that most strongly inform achievement behaviour and school grades (Mickelson, 1990). These perspectives are important to challenge an uncritical interpretation of aspirations as evidence of psychological dispositions to achieve, or of a simple causal relationship between aspirations and subsequent attainment. Nevertheless, the balance of evidence suggests a model of 'pragmatic rationality' taking a middle position that recognises the role of structural constraints but also the young persons own attitudes, predispositions and personal history (Payne, 2003).

This research does raise important implications for policy. Raising the aspirations of inner city children of secondary school age is one of the key aims of the current government's educational 
reform programme in the $\mathrm{UK}^{10}$. The current research suggests that educational aspirations are themselves strongly associated with some specific attitudes and influences that may underlie the link between aspirations and attainment. The key attitudinal factors from our data associated with low aspiration are low academic self concept, low home-educational aspirations, low peer support, disaffection and a lack of commitment to schooling. The differences in educational aspirations across ethnic groups are largely mediated by these factors, with contrasting cultures of aspiration within the home seen as a key mediator. For those groups where the home environment does not provide young people with the navigational capacity to aspire 'nurtured by the possibility of real-world conjectures and refutations', to re-use Appadurai's words, then the school is needed to fill the gap. The higher than expected aspirations of pupils in school 1 suggests that schools can have a positive impact on aspirations. However if the capacity to aspire is essentially a cultural capacity then it will require more than an additional strand of skills within the National Strategy; rather schools will need to re-assess themselves as cultural institutions and find ways to connect their normative values of aspiration with the lived curriculum of their pupils.

\section{References}

Addams, H., \& Johnson, M. (2005). London challenge: Surveys of pupils and teachers 2004. RR643. London: Department for Education and Skills.

Alloway, N., Gilbert, P., Gilbert, R. \& Muspratt, S. (2004) Factors impacting on student aspirations and expectations in Regional Australia, Department of Education, Science and Training, Commonwealth of Australia.

Appadurai, A. (2004) The Capacity to Aspire: Culture and the Terms of Recognition: in Rao V. \& Walton M. (eds) Culture and Public Action. Stamford University Press.

Blair, T. (2005) We must never concede the politics of aspiration for all, The Guardian, Friday, November $18^{\text {th }}, 2005,33$.

Bourdieu P. \& Passeron J.C. (1977). Reproduction in Education, Society and Culture Nice R. trans: London-Berverly Hills: Sage.

Cheng S. \& Starks, B. (2002) Racial Differences in the Effects of Significant Others on Students' Educational Aspirations, Sociology of Education, 75, (4), 306-327.

DfES (2006). Ethnicity and education. London: DfES. Retrieved from http://publications.teachernet.gov.uk/eOrderingDownload/DFES-0208-2006.pdf, 27th June 2007.

Fenton, S. (2003). Ethnicity. Cambridge: Polity Press.

10 In a recent article the Prime Minister Tony Blair writes 'New Labour today is the party of aspiration, for middle-class and poorer families; for all' (2005, p.33) 
Francis, B. \& Archer, L. (2005) British-Chinese pupils' and parents' constructions of the value of education, British Educational Research Journal, 31, (1), 89-108.

Garg, R., Kauppi, C., Lewko, J., \& Urajnik, D. (2002) A structural model of educational aspirations. Journal of Career Development, 29, (2), 87-108.

Hao, L. \& Bonstead-Bruns, M. (1998). Parent-child differences in educational expectations and the academic achievement of immigrant and native student. Sociology of Education, 71 , 175-198.

Hung C-L. \& Marjoribanks, K. (2005). Parents, teachers and children's social outcomes: a Taiwanese study, Educational Studies, 31, (1), 3-13.

Jowell, T. (2004). Government and the Value of Culture. Department for Culture Media and Sport (DCMS). Retrieved from http://www.culture.gov.uk/NR/rdonlyres/DE2ECA49-7F3D-46BF9D11-A3AD80BF54D6/0/valueofculture.pdf, 17th July 2007.

Kao, G. \& Tienda, M. (1998). Educational aspirations of minority youth. American Journal of Education, 106, 349-384.

Khattab, N. (2003). Explaining educational aspirations of minority students: the role of social capital and students' perceptions, Social Psychology of Education, (6), 283-302.

Khoo, S. T., \& Ainley, J. (2005). Attitudes, intentions and participation. Longitudinal Survey of Australian Youth. Victoria: Australian Council for Educational Research.

Leslie, D., \& Drinkwater, S. (1999). Staying on in Full-time education: Reasons for higher participation rates among ethnic minority males and females. Economica, 66, 63-77.

Marjoribanks, K. (2003). Family background, individual and environmental Influences. aspirations and young adults' educational attainment: a follow-up study. Educational Studies, 29, (2/3), 233-242.

McLeod, J. (1995) Ain't no makin' It: Aspirations and attainment in a low income neighbourhood. Boulder Colorado: Westview Press.

Mickelson, R. (1990). The attitude-achievement paradox among black adolescents. Sociology of Education, 63, 44-61.

Ogbu, J. (1978). Minority education and caste. New York: Academic Press.

Payne, J. (2003). Choice at the end of compulsory schooling: A review of research. RR414. London: Department for Education and Skills.

Penn, R. \& Scattergood, H. (2002). Ethnicity and career aspirations in contemporary Britain. New Community, 19, (1), 75-98.

Solorzano, D. (1992). An exploratory analysis of the effects of race, class and gender on student and parent mobility aspirations. Journal of Negro Education, 61, (1), 30-44.

Strand, S. (1999). Ethnic group, sex and economic disadvantage: Associations with pupils' educational progress from Baseline to the end of Key Stage 1. British Educational Research Journal, vol.25, no.2, 179-202. 
Strand, S. (2004). The use of effect sizes: Two examples from recent educational research. in Schagen, I. \& Elliott, K. (Eds) (2004). But what does it mean? The use of effect sizes in educational research. Slough: National Foundation for Educational Research.

Strand, S. (2007). Minority ethnic pupils in the Longitudinal Study of Young People in England. RR851. London: Department for Education and Skills.

US Census Bureau (2006). Current population reports, p60-231, Income, poverty and health insurance in the United States 2005. US Government Printing Office: Washington DC. Retrieved from http://www.census.gov/prod/2006pubs/p60-231.pdf on 7th July 2007.

Wentzel, K. R. (1998). Parents' aspirations for children's educational attainments: Relations to parental beliefs and social address variables. Merrill-Palmer Quarterly, 44, (1), 20-37. 